\title{
A Perfect Demonstration of the Absence of Leadership: Alcohol Policy in Ireland
}

\author{
Frank Houghton
}

Ir J Psych Med 2012; 29 (3): 145-146

February 2012 saw the publication of the Steering Group Report on a National Substance Misuse Strategy. ${ }^{1}$ This report represents the culmination of an earlier decision to finally acknowledge the true nature of alcohol and to include it within the wider context of substance misuse. The report is impressive, wide-reaching and should be welcomed.

However, the launch of this important report was notable by the lack of energetic and vocal support that it immediately received from Government. Opposition from the alcohol industry ${ }^{2,3}$ and their representative organisations ${ }^{4}$ was inevitable. Of greater concern though was the lack of endorsement of the report, combined with immediate efforts by four Government Ministers to undermine it. ${ }^{5}$ The Minister for State with responsibility for primary care only appeared briefly at the beginning of the launch before leaving, ${ }^{5}$ while the Minister for Health did not even attend the launch to offer support. ${ }^{6}$ The inclusion of numerous Government Departments on the Steering Group 1 makes the distancing of the Government from the report all the more bizarre.

An already established mountain of evidence exists clearly outlining the adverse impact of alcohol. ${ }^{7-9}$ A wealth of up-to-date evidence from Ireland exists which clearly demonstrates the negative impacts of alcohol here. ${ }^{10-14}$ Within the EU, which is the heaviest drinking region in the world, the Irish spend more of their income on alcohol than any other European country. ${ }^{8,15}$ In addition they are the most frequent binge drinkers in Europe, ${ }^{15}$ and have one of the highest rates of alcohol consumption in Europe..$^{8,16,17}$ Recent evidence suggests that one-quarter of Irish adults reported binge drink weekly, ${ }^{15}$ while over half of drinkers have been identified as having a harmful drinking pattern. ${ }^{18}$

Alcohol has been identified as killing approximately 88 people per month. ${ }^{11}$ This equates to almost one in twenty deaths (4.4 percent). ${ }^{11}$ Recent research also indicates that it results in 2,000 beds being occupied in acute hospitals in Ireland every night. ${ }^{1}$ This represents an estimated 10.3 percent of bed-days. ${ }^{12}$ Hope has identified that over a quarter (28 percent) of all injuries presenting to Accident \& Emergency Departments in the period 2003-2004 were recorded as being attributable to alcohol. ${ }^{19}$ Based on a costing for the year 2007 it has been estimated that alcoholrelated illness costs the healthcare system $€ 1.2$ billion per year. ${ }^{20}$ Other alcohol-related costs identified in Ireland include the costs of crime, lost economic output, and road traffic incidents. Based on 2007 figures these have been estimated to cost a total of $€ 1.19$ billion, $€ 527$ million, and $€ 530$ million respectively. ${ }^{20}$

Recent evidence from the National Registry of Deliberate Self Harm has also identified the significant adverse impact of alcohol in
Ireland.21 The 2010 Annual Report noted that alcohol was involved in 41 percent of all cases of deliberate self-harm, and in even more cases among males (44 percent). ${ }^{21}$ The association between alcohol and deliberate self-harm appears self-evident given the noted temporal pattern of $A \& E$ presentations. Presentations peaked around midnight on Sundays, Mondays and increasingly on or after public holidays.

Exploring the balance between the purported economic benefits of the alcohol industry ${ }^{22}$ and the costs of alcohol use and misuse in Irish society, the Steering Group on a National Substance Misuse Strategy recently concluded that 'the burden of health harms and the social consequences of harmful use of alcohol demanded the implementation of further measures to protect and preserve public health'.

Given the multi-faceted nature of the issue, it is not surprising that the Steering Group report is wide-ranging, making numerous recommendations across a host of fields. ${ }^{1}$ Perhaps the most notable of these are a ban on all alcohol sponsorship of sporting and large outdoor events, as well as a ban on outdoor advertising of aiconoi. Tine introduction of minimum pricing for aiconol is aiso advocated, as are higher excise duties on some alcohol products. The report also advocates a reduction in the recommended maximum weekly intake among both men and women (to 17 and 11 units respectively), and the introduction of a social responsibility levy. ${ }^{1}$

Ambivalent Government reaction to the Steering Group Report mirrors earlier indecisive responses to initiatives to reduce drinkdriving in 2008. ${ }^{23}$ Government statements concerning more effective control of alcohol in Ireland, which are subsequently found to be unmet, are hardly new in Ireland. Statements by Government suggesting initiatives to tackle the availability of alcohol in garages and service stations, ${ }^{24,25}$ the abolition of 'early houses', ${ }^{26}$ and the separation of off-licence sales in supermarkets have all failed to materialise. ${ }^{26}$ In 2008 rather than introducing the expected legal framework to govern alcohol advertising, placement and sponsorship, 24,25 the Irish Government opted instead to promote self-regulation. ${ }^{27-28}$ Despite protestations from the alcohol industry ${ }^{28}$ it was clear that tinkering and the appearance of action was clearly the aim of the exercise. ${ }^{27,28}$

The Irish Government's usual laissez-faire approach to the danger presented by alcohol is typified in a statement by the former Minister for Health, Mr Noonan, at the 1996 launch of the National Alcohol Policy ${ }^{29}$ when he stated that: "It's very hard to legislate for virtue. It's even difficult enough to legislate for good behaviour. The kind of island I would like to see is where we would 
have what I would describe as sovereign individuals who are well educated and mature and that when you give them information which is relevant to their own well-being they will make individual sovereign decisions in their own interest. I think that's the best approach." 30

However, Ireland can no longer afford to minimise the risks and adverse impact of alcohol. The time for posturing and rhetoric is over. It is no longer acceptable for government to simply mimic action. The last thing required now is another consultation exercise or research project. The facts are plain and the message is clear. Significant further controls on alcohol are required urgently. The Government needs to accept its role and duty to act as steward. ${ }^{31}$ It is imperative that the Government moves beyond the manipulative sectional self-interest of publicans and the alcohol industry and finally accepts its responsibility in the face of the threat of alcohol to safeguard and foster the health of its citizens.
References:

1. Department of Health. Steering Group Report on a National Substance Misuse Strategy. Dublin: Department of Health, 2012.

2. Alcohol Beverage Federation of Ireland. The National Substance Misuse Strategy Minority report by the Alcohol Beverage Federation of Ireland. Dublin: ABFI, 2012.

3. The Irish Times. Drinks sector, TDs object to report. February 6th 2012.

4. Mature Enjoyment of Alcohol in Society Limited (2012) National Substance Misuse Strategy 2009-2016 Minority Report by Mature Enjoyment of Alcohol in Society Limited. Dublin: MEAS.

5. The Irish Times. Call to limit alcohol sponsorship. February 7th, 2012.

6. The Irish Examiner. Concern over lack of support by Government. February 8th, 2012.

7. Anderson P, Møller L, Galea G. Alcohol in the European Union: Consumption, harm and policy approaches. Copenhagen: WHO Regional Office for Europe

8. Anderson P, Baumberg B. Alcohol in Europe: a public health perspective. London: Institute of Alcohol Studies, 2006.

9. Babor TF, Caetano R, Casswell S, Edwards G, Giesbrecht N, Graham K, Grube JW, Gruenewald PJ, Hill L, Holder HD, Homel R, Österberg E, Rehm J, Room R, Rossow I. Alcohol: No ordinary commodity - research and public policy. New York: Oxford University Press, 2003.

10. Lyons S, Lynn E, Walsh S, Sutton M, Long J. Alcohol-related deaths and deaths among people who were alcohol dependent in Ireland, 2004 to 2008. Dublin: Health Research Board, 2011.

11. Martin J, Barry J, Goggin D, Morgan K, Ward M, O'Suilleabhain T. Alcohol-attributable mortality in Ireland. Alcohol Alcohol 2010; 45: 379-86.

12. Martin J, Barry J, Skally M. Alcohol Attributable Hospitalisations and Costs in Ireland, 2000-2004. Ir Med J 2011; 104: 140-4.

13. Mongan $D$. The burden of alcohol-related morbidity on hospital services. Drugnet Ireland 2010; 35: 9-12.

14. Mongan D, Hope A, Nelson M. Social consequences of harmful use of alcohol in Ireland. HRB Overview Series 9. Dublin: Health Research Board, 2009.

15. Butler S. Tipping the Balance? An Irish Perspective on Anderson and Baumberg. Drugs: Education, Prevention and Policy 2006; 13: 493-497.

16. TNS Opinion and Social. EU citizens' attitudes towards alcohol. Special Eurobarometer, 331. Brussels: European Commission, 2010.

17. OECD Health Data 2011. http://stats.oecd.org/index.aspx?DataSetCode=HEALTH_STAT Accessed 2 December 2011.

18. Morgan K, McGee H, Dicker P, Brugha R, Ward M, Shelley E, Van Lente E, Harrington J, Barry M, Perry I, Watson D. SLÁN 2007: Survey of Lifestyle, Attitudes and Nutrition in Ireland. Alcohol use in Ireland: A profile of drinking patterns and alcohol-related harm from SLÁN 2007. Dublin: The Stationery Office, 2009.

19. Hope A. Alcohol-related harm in Ireland. Dublin: Health Service Executive - Alcohol Implementation Group. Dublin: Health Services Executive, 2008.

20. Byrne S. Costs to society of problem alcohol use in Ireland. Dublin: Health Service Executive, 2011

21. National Suicide Research Foundation. National Registry of Deliberate Self Harm Annual Report 2010. Cork: National Suicide Research Foundation, 2011.

22. Foley A. The economic contribution of the drinks industry. Dublin: Drinks Industry Group of Ireland, 2010.

23. The Irish Times. Political pressure hits new drink-drive policy. June 11th, 2008.

24. The Irish Times. Stricter rules on drinks sponsorship Government plan aims to restrict sale of alcohol. April 23rd, 2008.

25. The Irish Times. Government plan aims to restrict sale of alcohol. April 23rd, 2008.

26. The Irish Times. Government scraps plan to abolish 'early house' pubs. June 25th, 2008.

27. The Irish Times. Curbs on alcohol advertising to begin. July 1st, 2008.

28. The Irish Times. Drinks industry find new rules 'challenging'. July 7th, 2008.

29. Department of Health. National Alcohol Policy. Dublin: Stationery Office, 1996.

30. Butler S. (2009). Obstacles to the Implementation of an Integrated National Alcohol Policy in Ireland: Nannies, Neo-Liberals and Joined-Up Government. Journal of Social Policy 2009; 38(2): 343-359.

31. Jochelson K. Nanny or steward? The role of government in public health. Public Health 2006; 120(12): 1149-55. 